\title{
Commentary: When a choice is not an echo
}

Craig R. Smith, MD

From the Department of Surgery, Vagelos College of Physicians \& Surgeons of Columbia University, Columbia University Irving Medical Center of New York Presbyterian Hospital, New York, NY.

Disclosures: Smith was Surgical PI for the PARTNER 1 and 2 trials, and Surgical Chairman for the PARTNER 3 trial, for which he received reimbursement for travel and conventional expenses related to trial management. Received for publication March 21, 2019; accepted for publication March 21, 2019; available ahead of print April $20,2019$.

Address for reprints: Craig R. Smith, MD, Columbia University Irving Medical Center of New York Presbyterian Hospital, Milstein Building 7-435, 177 Fort Washington Ave, New York, NY 10032 (E-mail: crs2@cumc. columbia.edu).

J Thorac Cardiovasc Surg 2019;158:376-7

$0022-5223 / \$ 36.00$

Copyright (c) 2019 by The American Association for Thoracic Surgery

https://doi.org/10.1016/j.jtcvs.2019.03.067

In their article in this issue of the Journal, Chui and colleagues ${ }^{1}$ argue effectively that the lowering of the age threshold for appropriateness of tissue versus mechanical valves for surgical valve replacement (SVR) in various recent guidelines may have been overly aggressive, especially for mitral replacements. As they note, mitral bioprostheses are less durable than aortic bioprostheses. In addition, they make the important point that the transcatheter bailout procedure for failed mitral bioprostheses (mitral valve-in-valve [ViV] replacement) still faces several technical obstacles that contribute to the immaturity of mitral ViV relative to aortic ViV.

Chui and colleagues ${ }^{1}$ also mention risk of reoperation as one consideration underlying valve choice, citing markedly variable reported experience for surgical valves $(2.5 \%$ $14 \%),{ }^{1}$ which is nonetheless comparable at the higher end to recent reported experience with $\mathrm{ViV}(6.5 \%-7.6 \%)$. The risk of repeat procedures, however, will need to be redefined from scratch, beginning when transcatheter procedures have a well-established role across the entire risk spectrum. The risks associated with redo SVR after SVR, ViV after SVR, SVR after ViV, and ViV after a transcatheter procedure may differ markedly, or they may not. It is almost certain that SVR after any other procedure will be restricted to a lower risk population than in the past, as ViV siphons off higher risk cases whenever technically feasible.

What is behind the recent flurry of guidelines adjustments in age thresholds for tissue valves? Justification for all transcatheter valve procedures requires that tissue valves be at least equivalent to mechanical valves in the categories of patients under consideration. By applying the transitive property, lowering the age threshold of equivalence for surgical tissue valves improves market share for transcatheter valves. This sets up the delicious irony of cardiologists waxing passionately on the "avoid dread warfarin" virtues of tissue valves while simultaneously driving a pandemic of

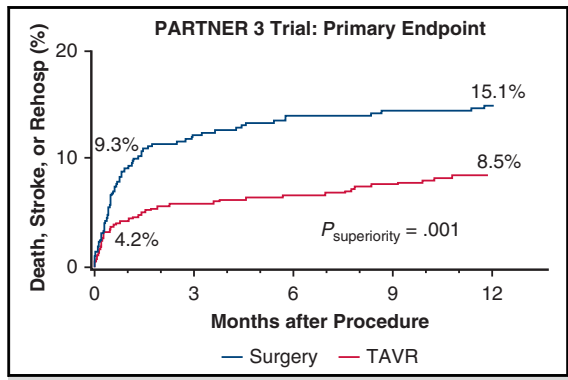

The combined end point of death, stroke, and rehospitalization in the PARTNER 3 trial.

\section{Central Message}

The choice between mechanical and tissue valves is still relevant, and current guidelines overemphasize the role of tissue valves.

See Article page 368

anticoagulation, to treat fear of atrial fibrillation, that will soon have triple therapy in our water supply. Once the entire planet is anticoagulated, a primary virtue of tissue valves (setting aside noise abatement) will be that transcatheter cardiologists and surgeons can put them in-and then put them in again, again, and again — angioplasty redux!

Whether driven by motivations cynical or pure, debating surgical valve choice may seem an increasingly quaint topic. I doubt that anyone reading these words missed the

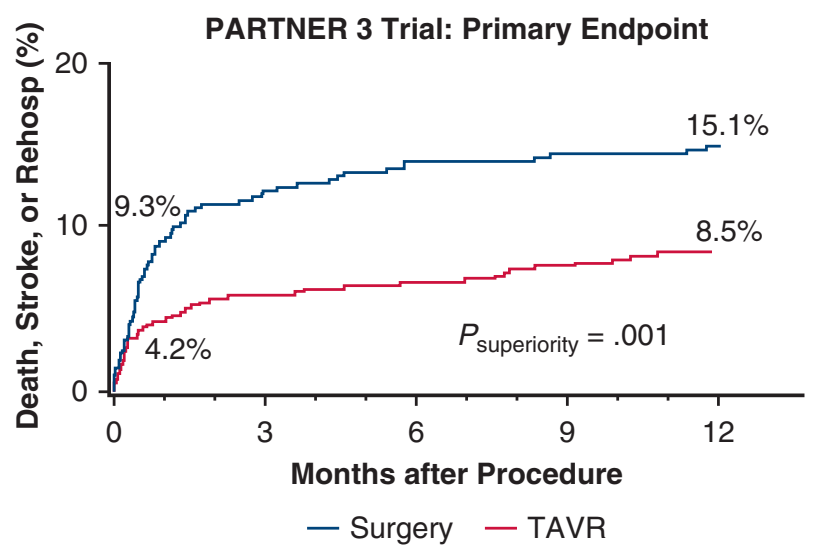

FIGURE 1. The combined end point of death, stroke, and rehospitalization (Rehosp) in the PARTNER 3 (The Safety and Effectiveness of the SAPIEN 3 Transcatheter Heart Valve in Low Risk Patients With Aortic Stenosis) trial. TAVR, Transcatheter aortic valve replacement. 
thunderclap on March 17, 2019, at the meeting of the American College of Cardiology when transcatheter aortic valve replacement demonstrated superiority relative to surgical aortic valve replacement in 2 large, randomized trials composed of low-risk patients (Figure 1). ${ }^{2,3}$ This confirms that surgical aortic valve replacement is becoming a niche procedure. Within the niche, however, and in patients with mitral valve disease, it will remain important to define the appropriate boundaries between mechanical and tissue valves in SVR.

\section{References}

1. Chiu P, Goldstone AB, Fischbein MP, Woo JY. Current evidence for prosthesis selection: what can we really say? J Thorac Cardiovasc Surg. 2019; 158:368-75.

2. Popma JJ, Deeb GM, Yakubov SJ, Mumtaz M, Gada H, O’Hair D, et al; Evolut Low Risk Trial Investigators. Transcatheter aortic-valve replacement with a self-expanding valve in low-risk patients. N Engl J Med. March 17, 2019 [Epub ahead of print].

3. Mack MJ, Leon MB, Thourani VH, Makkar R, Kodali SK, Russo M, et al; PARTNER 3 Investigators. Transcatheter aortic-valve replacement with a balloon-expandable valve in low-risk patients. $N$ Engl J Med. 2019;380: 1695-705. 